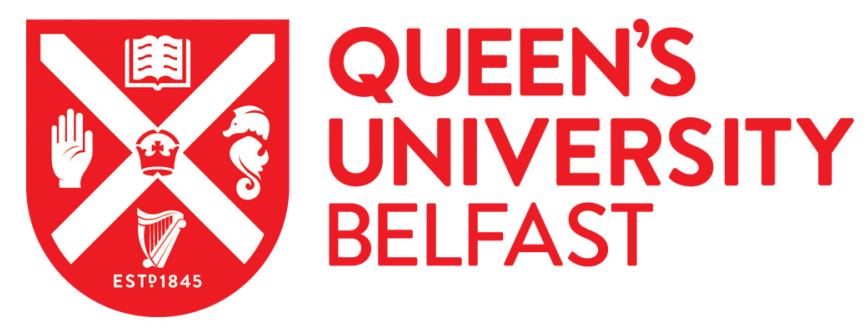

\title{
Prenatal surgery for spina bifida: a therapeutic dilemma. Proceedings of the SHINE conference, Belfast
}

\author{
Shanmuganathan, M., Sival, D. A., Eastwood, K-A., Morris, K., Cartmill, J., Heep, A., Bohosiewicz, J., \\ Pastuszka, A., Hunter, A., Ali, A., McConnell, R., Crimmins, D., Malone, F., Bailie, C., Deprest, J., McKillop, C., \\ Alfirevic, Z., McAuliffe, F., \& Ong, S. (2017). Prenatal surgery for spina bifida: a therapeutic dilemma. \\ Proceedings of the SHINE conference, Belfast. Irish journal of medical science, 1-6. \\ https://doi.org/10.1007/s11845-017-1709-6 \\ Published in: \\ Irish journal of medical science
}

Document Version:

Peer reviewed version

Queen's University Belfast - Research Portal:

Link to publication record in Queen's University Belfast Research Portal

Publisher rights

Copyright 2017 Springer Verlag. This work is made available online in accordance with the publisher's policies. Please refer to any applicable terms of use of the publisher.

\section{General rights}

Copyright for the publications made accessible via the Queen's University Belfast Research Portal is retained by the author(s) and / or other copyright owners and it is a condition of accessing these publications that users recognise and abide by the legal requirements associated with these rights.

Take down policy

The Research Portal is Queen's institutional repository that provides access to Queen's research output. Every effort has been made to ensure that content in the Research Portal does not infringe any person's rights, or applicable UK laws. If you discover content in the Research Portal that you believe breaches copyright or violates any law, please contact openaccess@qub.ac.uk. 


\section{Prenatal surgery for spina bifida; a therapeutic dilemma. Proceedings of the SHINE conference, Belfast}

Authors: Mano Shanmuganathan ${ }^{1}$, Deborah A. Sival ${ }^{2}$, Kelly-Ann Eastwood ${ }^{c}$, Katie Morris $^{4}$, Jacqueline Cartmill 5 , , Axel Heep ${ }^{6}$, Janusz Bohosiewicz ${ }^{7}$, Agnieszka Pastuszka $^{8}$, Alyson Hunter ${ }^{3}$, Amanda Ali ${ }^{9}$, Roy McConnell ${ }^{1}$, Darach Crimmins ${ }^{10}$, Fergal Malone ${ }^{11}$, Carolyn Bailie ${ }^{3}$, Jan Deprest ${ }^{12,13}$, Cathy McKillop ${ }^{14}$, Zarko Alfirevic $^{15}$, Fionnuala McAuliffe ${ }^{16}$, Stephen Ong ${ }^{3}$

1. Department of Neurosurgery, Royal Victoria Hospital, Belfast, U.K.

2. The Beatrix Children's Hospital University Medical Center Groningen, University of Groningen, Netherlands

3. Fetal Medicine, Royal Jubilee Maternity Hospital, Grosvenor Road, Belfast BT12 6BB, UK

4. Institute of Metabolism and Systems Research, University of Birmingham and West Midlands Fetal Medicine Centre, Birmingham Women's Hospital NHS Foundation Trust, Birmingham UK

5. Altnagelvin Hospital, Londonderry, Northern Ireland.

6. Southmead Hospital, North Bristol NHS Trust/,School of Clinical Sciences, University of Bristol/ Technical University Munich, Germany

7. High School of Strategic Planning in Dabrowa, Gornicza, Poland

8. School of Medicine with Division of Dentistry in Zabrze, Department of Descriptive and Topographic Anatomy, Medical University of Silesia, Katowice, Poland

9. Kingston Hospitals NHS Foundation Trust, UK

10. Neurosurgery unit, Temple Street Children's University Hospital, Dublin, Ireland

11. The Rotunda Hospital/ Royal College of Surgeons in Ireland, Dublin, Ireland

12. Department of Obstetrics and Gynaecology, University Hospitals Leuven, Leuven, Belgium

13. Research Department of Maternal Fetal Medicine, UCL Institute for Women's Health, University College London, London, UK

14. SHINE, the Spina Bifida Charity, UK

15. Department of Women's and Children's Health, University of Liverpool and Liverpool Women's Hospital, UK

16. National Maternity Hospital/ University College Dublin, Ireland

Short title: Therepeutic dilemmas regarding prenatal surgery for spina bifida

Key words: Spina bifida, prenatal surgery, open prenatal surgery, fetoscopic surgery, postnatal surgery

\section{Corresponding author:}

Stephen Ong

Stephen.ong@belfasttrust.hscni.net 
Royal Jubilee Maternity Hospital, Grosvenor Road, Belfast BT12 6BB, U.K. Tel: $0044(0) 7949178548$

\section{Objective, Setting and Participants}

Evidence suggests that prenatal surgery for spina bifida aperta (SBA) may confer an improved outcome(1). Available interventions are however not without fetal and maternal risks. The purpose of this conference was to bring together those skilled in prenatal open or minimally invasive fetoscopic SBA repair and standard postnatal repair to allow description of the current evidence for perinatal management of spina bifida. The conference also aimed to reach a consensus regarding clinicians' approach to counselling and to identify future areas of research.

In the North and South of Ireland, the incidence of spina bifida is high (approximating 50 live births per year). The conference was held on Tuesday the $7^{\text {th }}$ of June 2016 in the Emeleus lecture theatre at Queen's University, Belfast, Northern Ireland. The meeting was organised by SHINE, the spina bifida charity in the UK.

Invited speakers included fetal surgeons experienced in open and minimally-invasive fetal surgery for spina bifida and paediatric neurosurgeons performing postnatal repairs. Additional lectures were given by a neonatologist, a paediatric neurologist and an obstetrician experienced in clinical trials and systematic reviews. Mothers who had experienced prenatal surgery were also interviewed.

Participants included fetal medicine specialists, neonatologists, paediatricians, paediatric surgeons, urological surgeons, orthopaedic surgeons, neurosurgeons, neurologists, radiologists, general practitioners, public health specialists, statisticians, physiotherapists, occupational therapist, midwives, nurses and radiographers. There were 130 participants in total from Ireland, the UK, and other European countries.

The morning session opened with a summary of the Management of Myelomeningocele Study (MoMs) and ancillary papers. This was followed by the Polish experience of open prenatal surgery and the German experience of fetoscopic 
surgery. The neonatal outcomes after fetoscopic surgery were presented by a neonatologist. In addition, a paediatric neurologist argued that not all complications of spina bifida can be alleviated by prenatal surgery.

The afternoon session commenced with the Belgian experience of open prenatal surgery and challenges associated with follow-up and delivery in other units. This was followed by the German referral pathway for fetoscopic surgery. A comparison between open and fetoscopic surgery was presented followed by a presentation outlining the difficulties in evaluating novel surgical procedures.

Central to the conference was hearing first-hand the experience of mothers and their families who had been affected by SBA. Two women who experienced fetoscopic prenatal surgery gave testimonies and were interviewed at the conference using a standardised questionnaire. They also brought their baby/ child to the meeting. One woman who experienced open prenatal surgery, but was not able to attend, answered questions from the same standardised questionnaire and presented a video of her child demonstrating her experience and her child's progress postoperatively. All three women were very positive about their experience and spoke highly of the staff in the respective prenatal surgical units.

The evening session was chaired by a fetal medicine specialist experienced in clinical trials. The audience also debated the future of research into the management of SBA.

\section{Summary of MoMs trial}

A summary of the MoMs (Management of Myelomeningocoele study) randomised trial was presented by Dr Kelly-Ann Eastwood (clinical research fellow), which indicated a reduction of need for shunting and an improvement in hindbrain herniation by 12 months of age for women that had prenatal surgery(1). Prenatal surgery also resulted in improvement in the composite score for mental development 
and motor function at 30 months. Dr Eastwood presented additional publications from the MoMs team, reporting on urinary function(2) and on requirement for shunting as a function of ventricular dilatation(3). The main benefit of fetal surgery is related to the level of the lesion and ventricular size(3). It is also apparent that a posterior ventricular width of $>15 \mathrm{mms}$ confers no improvement in postnatal shunting although other outcomes remain.

The MoMs 2 trial will study the longer term effects of fetal surgery as well as the reproductive health of the mother.

\section{Is open prenatal surgery the obvious choice?}

Professor Janusz Bohosiewicz (paediatric surgeon and fetal surgeon) and Dr Agnieszka Pastuszka (paediatric urologist and fetal surgeon) from Poland presented their experience of open fetal surgery for spina bifida in 69 cases operated on between 2005 and 2014. Prerequisites for surgery included: Chiari II malformation, evidence of hindbrain herniation, absence of other congenital malformation and gestational age between 20 and 26 weeks. The group initially used magnesium sulphate for tocolysis, but more recently adopted the use of nifedipine as this was associated with fewer complications. The team reported that neonatal outcomes from their most recent case series were comparable to that of the MoMs trial(4). Shunt dependent hydrocephalus at age 12 months was $21 \%$ in comparison to $52 \%$ in neonates operated on postnatally. Preliminary data suggesting improvement at two years for those receiving prenatal surgery was also presented.

Post-operative urological results were presented: no difference was found in urodynamic tests or cysto-urethrography between the prenatal and postnatal groups. However, children who were operated on prenatally were 'socially' more continent than those operated on postnatally. Similar results were reported for post-operative bowel function. The Polish group argued against fetoscopic surgery as they felt this did not achieve the anatomical closure achieved by standard postnatal surgery. 
Comment was made on the high fetal mortality at the beginning of the Polish program. However this has improved significantly in recent years. There were no serious incidences of maternal morbidity or mortality.

\section{Does minimally invasive fetoscopic surgery achieve the same outcome with less maternal morbidity?}

The 'two hit hypothesis' in spina bifida was re-iterated by Professor Thomas Kohl (fetal surgeon). If the defect is closed early, normal distribution of cerebrospinal fluid is restored, thereby correcting hindbrain herniation and improving neurodevelopment. The fetoscopic technique of 'single or double patch closure' with a collagen patch or a collagen patch-over-teflon-patch(5) with minimal morbidity to the mother(6) was described by Professor Kohl. For this procedure, the fetus is reached via three trocars with an external diameter of $5 \mathrm{~mm}$, obviating the need for maternal laparotomy and hysterotomy.

Challenging the belief that open fetal surgery may be better for the fetus because it provides anatomical closure of the SBA, as recommended in standard postnatal surgery; an experimental study in sheep was cited by Professor Kohl. In this study by Pedreira and colleagues from Sao Paulo, the standard postnatal approach was associated with additional damage to the neural placode in contrast to a simplified fetoscopic approach(7). In the later part of the German series from July 2010 to 2014 there were no procedure related losses in 71 cases, with results apparently comparable to the MoMs trial(8). The most common complication was amniotic fluid leakage and preterm delivery, the latter occurring at an average of 33 weeks of gestation(5). Postnatal demise were attributed to infection (2 cases), trisomy 13 (1 case) and brain-stem dysfunction from severe hind brain herniation (4 cases). The fee for the fetoscopic procedure is $€ 5,500$ for women outside of Germany. The total admission cost is $€ 14,000$. For German residents, the procedure is paid for by a special health insurance program (NUB). 
Professor Kohl voiced his personal view that in countries where the laws on termination of pregnancy are restrictive, the state has a moral obligation to provide funding for prenatal surgery if this is not available locally. This view was not shared by all speakers.

\section{Evaluating neurological outcome following fetoscopic surgery}

The aetiology of spina bifida and associated morbidity, for example, ventriculitis and meningitis was discussed by Professor Axel Heep (consultant neonatologist). There is a wide variation between segmental anatomical lesions (as assessed with ultrasound and/or MRI) and functional neurological outcome. When comparing children that had undergone fetoscopic closure in Germany during pregnancy with lesion height-matched control groups of postnatally operated children, there was a statistically significant better sensory and motor function in the fetoscopic group, with better preservation of knee jerk and anal reflexes. In addition, there was a $50 \%$ lower prevalence of shunt dependent hydrocephalus (9). These results are consistent with findings from the MoMs trial.

\section{Neuropathology of pre-existing lesions and why prenatal surgery may not improve outcome in all cases}

Dr Deborah Sival (consultant in paediatric neurology) explained that in fetal SBA, prenatal surgery may not cure all pre-existing neuro-developmental pathology. After incomplete closure of the neural tube, successive neuro-developmental abnormalities (such as ependymal denudation, neuronal stem cell loss, impaired neuronal migration and aberrant segmental spinal blood vessels)(10) are unlikely to be reversed by fetal surgical closure(9). Although fetal surgery can prevent Chiari-2 malformation, hydrocephalus and neurological consequences by avoiding the second hit of spinal damage, not all pre-existing neuropathology may be curatively 
addressed by it. It has been previously shown that fetal surgery can result in motor function gain (equivalent to a median of 2 spinal segments)(9). In case of a myelomeningocele at a lumbar level, such a motor function gain could result in maintained ambulation. However, long term observational data from fetoscopic surgery are still incomplete and a randomised controlled study has not yet been performed. Analogous to the natural history of postnatally operated spina bifida aperta, it cannot be excluded that ambulation deteriorates when the child ages and increases in weight and length. Moreover, prenatally operated babies are at risk of loss of ambulation (related to de-tethering procedures, trauma, syringomyelia, arachnoid cysts, epidermoid tumours) in the same way as postnatally operated infants. Further research into the long-term outcome of prenatal surgery is therefore pertinent.

\section{Is the evidence for prenatal surgery lacking? Is standard postnatal surgery best for mother and baby?}

Currently, the almost unavoidable risks of prenatal surgery are preterm rupture of membranes and premature delivery. Despite these risks, regardless of an open or fetoscopic surgical approach, more than $85 \%$ of prenatally operated children with SBA are born beyond 30 weeks of gestation and half of them, beyond 33 weeks of gestation. With modern neonatal services, the risk of serious morbidity relating to prematurity at early gestations is relatively low.

Dr Alyson Hunter (consultant in fetal medicine) explained that there are, additional but rare complications $(<5 \%)$ including fetal death at surgery, serious maternal sepsis and haemorrhage. In earlier case series, fetal death rates seemed higher in fetoscopic surgery compared with open surgery. Recent data has not upheld this observation(8). The main complication of fetoscopic surgery is preterm rupture of membranes leading to a mean age of delivery that is approximately one week earlier than after open fetal surgery. For open fetal surgery, uterine scar dehiscence and rupture are major concerns. 
An overview of standard postnatal surgery by Dr Roy McConnell (consultant neurosurgeon) included all cases of spina bifida in Northern Ireland over the past 15 years. Comment was made on the follow up of two babies born in Belfast following fetocopic surgery abroad. Both babies developed meningitis and required shunting. It was concluded that more research is needed in this field and that both prenatal methods appear to be viable options. Following discussion, it was suggested that a two stage process: fetoscopic surgery combined with postnatal skin closure above the patch may represent a future advance in this field.

\section{Implementing open fetal surgery in collaboration with the referring unit}

An overview of spina bifida surgery in Belgium was provided by Professor Jan Deprest (consultant in fetal medicine and fetal surgeon). The role of tertiary centres, and diagnosis and training was discussed. A description was given of the framework of peri and postnatal management and the mixed training model where surgeons train on site (such as in the United States) and return to their index hospital with support from a visiting trainer(11). The Belgian unit adheres strictly to the same selection criteria used in the MoMs trial (Table 1). Recently, the upper body mass index limit has been raised from 35 to $40 \mathrm{~kg} / \mathrm{m}^{2}$ as operator experience has improved. Women with a previous caesarean section are not excluded per se.

The management protocol in Belgium was outlined; a standard hysterotomy is performed and the neural tube surgery is performed by the neurosurgeon. Atosiban and nifedipine are used for tocolysis, succesfully reducing maternal side effects. In up to $20 \%$ of cases, a colloid patch is used instead of formal closure of the spina bifida defect. Women are referred back to their local institution for delivery, which is by elective caesarean section. Women are advised to allow two years before planning their next pregnancy. The unit in Belgium have a standardised information brochure and a standardised checklist for counselling. Their outcomes were similar 
to the results obtained in the MOMs trial. This includes a $5 \%$ perinatal death rate, gestational age at birth of approx. 34 weeks of gestation, with $10 \%$ delivering at less than 30 weeks. The fee for the procedure is $€ 2,800$; the total admission cost is $€ 9,500$. Women from outside of Belgium are charged the same as a Belgian citizen with no additional fee payable. To date, all EU citizens have had their fee reimbursed by their local insurance companies. About 1:3 women who were referred for an opinion and who met the criteria for surgery subsequently declined fetal surgery after counselling. It was stated that in the future all women, including women who have had fetal surgery, will 'own' a virtual electronic record which will enable improved follow up of these cases. This initiative was supported by delegates and it was proposed that a national registry for these cases should be instigated for fetuses operated by either open or the fetoscopic approach.

Discussion took place regarding funding from local health boards for prenatal surgery, with some individuals advocating routine state funding and others opposing routine funding until further scientific evidence is available.

\section{Referral pathway and patient selection for fetoscopic surgery in Germany}

Professor Thomas Kohl (fetal surgeon) explained that at DFZT in Germany, there are strict prerequisites for surgery, including, a singleton pregnancy, a body mass index $<40 \mathrm{~kg} / \mathrm{m}^{2}$ and no risk of transmissible infection, such as HIV/Hepatitis. The pathway includes detailed counselling by the prenatal team, the neuropaediatrician and the prenatal surgical team. The woman is provided with contact details to aid her in decision making. An outline of the admission procedure at 24 weeks gestation (prior to surgery) is provided. A description was given of the difficult choices women face when there are co-existing problems such as trisomy 21 .

There was a comment from the neurosurgical chair, Mr Darach Crimmins (consultant neurosurgeon) that the selection criteria for prenatal surgery - regardless if open or 
fetoscopic- seemed to encompass the 'easy' patients. He observed that in these cases, postnatal surgery is also likely provide a good outcome, and that the most challenging patients from a neurosurgical point of view were in fact excluded from prenatal surgery.

\section{Systematic review of effects of open and \& fetoscopic surgery}

An overview of open and fetoscopic techniques was presented by Professor Jan Deprest (consultant in fetal medicine and fetal surgeon). A comparison was made between different fetoscopic techniques from Germany, Brazil, USA and Spain. Fetoscopic surgery was compared to the techniques used in the MoMs trial (open fetal surgery), with reference to in-utero demise, maternal complications, uterine dehiscence, reversal of Chiari and shunt rate(12). It was concluded that with open repair there is conclusive evidence of a reduced shunt rate and neuroprotection. However, open surgery has significant maternal morbidity and implications for the next pregnancy. Fetoscopic surgery has a reduced risk of maternal morbidity, but takes longer and has a higher initial failure rate. Fetoscopic surgery also has a longer learning curve, higher rate of premature rupture of membranes and a slightly earlier delivery rate. There are also no controlled series comparing fetoscopic surgery to expectantly managed cases or to open surgery.

\section{Interpreting the evidence from systematic reviews of novel surgical techniques}

Evidence based medicine in surgical interventions was discussed by Dr Katie Morris (consultant in fetal medcine). A description was provided of the barriers to conducting randomised controlled trials in evaluation of novel surgical techniques. These included: operator learning curves, standardisation, evolution of surgical technique and funding. Systematic reviews are a powerful tool to assess evidence 
but the results are limited by the power of the included studies(13; 14). The parameters to be met for fetal intervention include accurate diagnosis and differentiation from other nonsurgical conditions, and the risk of severe debilitating disease if left untreated. Examples of trials of surgical interventions in fetal medicine were cited $(15 ; 16)$.

\section{What research do we need and what should we tell women?}

Professor Zarko Alfirevic (consultant in fetal medicine) chaired the final session where discussion took place regarding a randomised controlled trial of fetosocopic surgery vs. open fetal surgery and the outcome measures required. It became clear that even for established postnatal surgical techniques in children with spina bifida, there remain no standardised methods of reporting outcome. The audience was unanimous regarding prenatal counselling of women who have pregnancies complicated by SBA; it was felt that women with a diagnosis of fetal spina bifida should be informed that prenatal surgery is an alternative option to standard postnatal surgery.

\section{Implications for current practice}

1) The outcome of postnatal surgery must be reported in a standardised manner.

2) Further data is required regarding the long term neonatal outcome following open prenatal surgery (MoMs 2 trial).

3) Further data is required regarding the long term maternal outcome and impact on future pregnancy following open prenatal surgery.

4) Pregnant women with a fetus known to have spina bifida should be counselled that prenatal surgery is an option in specific circumstances. 


\section{Research recommendations}

5) Further and controlled data is required regarding the medium and long term outcome following fetoscopic surgery.

6) Agreed definitions of important child outcomes reflecting quality of life are required from a modern series of postnatally corrected lesions to allow comparison with fetal surgery.

7) Consideration should be given to the concept of fetoscopic surgery followed by additional surgical skin closure above the patch postnatally.

8) Standardised outcome measures of fetoscopic, open and postnatal surgery should be agreed so that these outcomes can be compared.

9) Good quality observational studies of open, fetoscopic and postnatal surgery using standardised outcome measures are required prior to a further randomised controlled trial. This will also allow refinement of surgical technique such as fetoscopic surgery in conjunction with postnatal skin closure above the patch. 10) After accomplishing the points 1) to 9), consideration should be given to a randomised controlled trial comparing fetoscopic and open prenatal surgical repair (although good quality observational data may make a randomised trial ethically impossible to perform). 


\section{Declaration of conflict of interest:}

JB and JD are proponents of prenatal surgery and DC, MS, RM are proponents of postnatal surgery. These authors do not stand to gain financially or otherwise. All other authors declare no conflict of interest.

\section{Disclosure:}

This is a transcript of a scientific meeting. Not all authors agree with all statements in this paper

\section{Sponsorship/ Funding:}

MDI Medical, Public Health Agency Northern Ireland, Perinatal Trust Fund Northern Ireland, SHINE

\section{Contribution to authorship:}

SO confirms that this is an honest, accurate and transparent account of the meeting being reported. SO, CM, JC organised the meeting with others. AA wrote the first draft of the report. CB, KAE, JB, AP, AxH, DAS, AH, RM, JD, RKM presented data to the meeting. FM, MS, FMcA, DC, ZA chaired and directed discussion during the meeting. All authors contributed to the discussion, edited the report and approved the final version.

\section{Ethical approval}

Not required.

\section{Acknowledgement:}

The authors wish to thank the women that agreed to be interviewed at this conference. The authors also wish to thank Mrs Cathy McKillop from SHINE, the spina bifida charity, for facilitating and organising this meeting. We wish to thank Professor Thomas Kohl for his invaluable contribution regarding fetoscopic surgery at this meeting. 
Table 1) Selection criteria for open fetal surgery for myelomenigocoele in Belgium

\begin{tabular}{|l|}
\hline Inclusion criteria \\
\hline Maternal age $\geq 18$ years \\
Gestational age 19 to 25 weeks and 6 days ( 21 to 26 weeks 6 days in Poland) \\
Normal genetic testing ( conventional karyotype and array analysis) \\
Above $\mathrm{S} 2$ and below T1 ( Below T12 in Poland) \\
Confirmed Chiari malformation type II on magnetic resonance imaging \\
\hline Exclusion criteria \\
\hline Multiple pregnancy \\
Insulin dependent pregestational diabetes \\
Additional structural anomalies unrelated to myelomenigocoele \\
Fetal kyphosis $\geq 30$ degrees \\
History of incompetent cervix \\
Cervical length $<2$ cm in index pregnancy \\
Preterm labour $<37$ weeks in previous singleton pregnancy \\
Placenta praevia \\
Other serious maternal medical complications \\
Body mass index $>40$ \\
Red cell alloimmunisation \\
Positive serology for human immunodeficiency, hepatitis B or C virus \\
Uterine anomaly \\
Psychosocial limitations \\
\hline \\
\hline *previous Caesarean section is not a contraindication \\
\hline
\end{tabular}




\section{References}

1. Adzick NS, Thom EA, Spong CY, Brock JW, 3rd, Burrows PK, et al. 2011. A randomized trial of prenatal versus postnatal repair of myelomeningocele. $N$ Engl $J$ Med 364:993-1004

2. Brock JW, 3rd, Carr MC, Adzick NS, Burrows PK, Thomas JC, et al. 2015. Bladder Function After Fetal Surgery for Myelomeningocele. Pediatrics 136:e906-13

3. Tulipan N, Wellons JC, 3rd, Thom EA, Gupta N, Sutton LN, et al. 2015. Prenatal surgery for myelomeningocele and the need for cerebrospinal fluid shunt placement. $J$ Neurosurg Pediatr 16:613-20

4. Zamlynski J, Olejek A, Koszutski T, Ziomek G, Horzelska E, et al. 2014. Comparison of prenatal and postnatal treatments of spina bifida in Poland--a non-randomized, single-center study. J Matern Fetal Neonatal Med 27:1409-17

5. Kohl T. 2014. Percutaneous minimally invasive fetoscopic surgery for spina bifida aperta. Part I: surgical technique and perioperative outcome. Ultrasound Obstet Gynecol 44:515-24

6. Degenhardt J, Schurg R, Winarno A, Oehmke F, Khaleeva A, et al. 2014. Percutaneous minimal-access fetoscopic surgery for spina bifida aperta. Part II: maternal management and outcome. Ultrasound Obstet Gynecol 44:525-31

7. Herrera SR, Leme RJ, Valente PR, Caldini EG, Saldiva PH, Pedreira DA. 2012. Comparison between two surgical techniques for prenatal correction of meningomyelocele in sheep. Einstein (Sao Paulo) 10:455-61

8. Graf K, Kohl T, Neubauer BA, Dey F, Faas D, et al. 2016. Percutaneous minimally invasive fetoscopic surgery for spina bifida aperta. Part III: neurosurgical intervention in the first postnatal year. Ultrasound Obstet Gynecol 47:158-61

9. Verbeek RJ, Heep A, Maurits NM, Cremer R, Hoving EW, et al. 2012. Fetal endoscopic myelomeningocele closure preserves segmental neurological function. Dev Med Child Neurol 54:15-22

10. Sival DA, Guerra M, den Dunnen WF, Batiz LF, Alvial G, et al. 2011. Neuroependymal denudation is in progress in full-term human foetal spina bifida aperta. Brain Pathol 21:163-79

11. Ovaere C, Eggink A, Richter J, Cohen-Overbeek TE, Van Calenbergh F, et al. 2015. Prenatal diagnosis and patient preferences in patients with neural tube defects around the advent of fetal surgery in Belgium and Holland. Fetal diagnosis and therapy 37:226-34

12. Joyeux L, Engels AC, Russo FM, Jimenez J, Van Mieghem T, et al. 2016. Fetoscopic versus Open Repair for Spina Bifida Aperta: A Systematic Review of Outcomes. Fetal diagnosis and therapy 39:161-71

13. Morris RK, Malin GL, Khan KS, Kilby MD. 2010. Systematic review of the effectiveness of antenatal intervention for the treatment of congenital lower urinary tract obstruction. BJOG 117:382-90

14. Roberts D, Gates S, Kilby M, Neilson JP. 2008. Interventions for twin-twin transfusion syndrome: a Cochrane review. Ultrasound Obstet Gynecol 31:701-11

15. Senat MV, Deprest J, Boulvain M, Paupe A, Winer N, Ville Y. 2004. Endoscopic laser surgery versus serial amnioreduction for severe twin-to-twin transfusion syndrome. $N$ Engl J Med 351:136-44

16. Morris RK, Malin GL, Quinlan-Jones E, Middleton LJ, Hemming K, et al. 2013. Percutaneous vesicoamniotic shunting versus conservative management for fetal lower urinary tract obstruction (PLUTO): a randomised trial. Lancet 382:1496-506 
